\title{
Distribuição de raízes de coqueiro anão sob volumes de água em solo coeso dos tabuleiros
}

\author{
$\overline{\text { Fernando L. D. Cintra' }^{1} \text {, Ronaldo S. Resende }{ }^{1}, \& \text { Maria de L. da S. Leal }}{ }^{1}$
}

\begin{abstract}
RESUMO
Propõe-se com este estudo, avaliar o efeito de volumes de água aplicados por microaspersão, em solo coeso dos Tabuleiros Costeiros, no aprofundamento das raízes de coqueiro anão verde. O estudo foi desenvolvido no Distrito de Irrigação Platô de Neópolis, no qual foram testados três volumes de água de irrigação (150, 100 e $50 \mathrm{~L} \mathrm{~d}^{-1}$ ), no delineamento inteiramente casualizado com quatro repetições. Utilizaram-se o método de trincheira e o software SIARCS para medição da densidade das raízes ( $\mathrm{cm}$ de raízes por $0,56 \mathrm{~m}^{2}$ de área de quadrícula) em profundidade e com os resultados obtidos, concluiu-se que o menor volume de água $\left(50 \mathrm{~L} \mathrm{~d}^{-1}\right)$ foi insuficiente para romper a expressão do adensamento das camadas coesas resultando em impedimento ao aprofundamento das raízes; este impedimento foi menos evidente nos volumes de 100 e $150 \mathrm{~L}$, os quais apresentaram comportamentos similares entre si e melhores condições de desenvolvimento lateral e em profundidade das raízes.
\end{abstract}

Palavras-chave: sistema radicular, microaspersão, microirrigação, irrigação, tabuleiros costeiros

\section{Distribution of dwarf coconut roots under water volumes in a hardened soil of the Tablelands}

\begin{abstract}
The objective of this research was to evaluate the effect of different water volumes, applied by micro sprinkler in a hardened Coastal Tableland soil, on the distribution of green-dwarf coconut roots. The study was carried out in the "Platô de Neópolis" Irrigation District. Three irrigation water volumes (150, 100, and $50 \mathrm{~L} \mathrm{~d}^{-1}$ ) were tested in a completely randomized design, with 4 replicates. The pit method and the software SIARCS were used to measure the density of roots ( $\mathrm{cm}$ root per $0.56 \mathrm{~m}^{2}$ of quadrant area) through the soil profile. The results obtained lead to the conclusion that the smallest water volume $\left(50 \mathrm{~L} \mathrm{~d}^{-1}\right)$ was not sufficient to overcome the expression of the hardened layers, which resulted in a restriction to the root deepening. This restriction was less evident in the volumes of 100 and $150 \mathrm{~L}$, which presented a very similar behavior and provided better conditions for the development of roots, both laterally and in depth.
\end{abstract}

Key words: root, micro sprinkler, micro irrigation, irrigation 


\section{INTRODUÇÃO}

A expansão do agronegócio do coqueiro anão verde irrigado nos tabuleiros costeiros enfrenta vários problemas, dentre os quais se destacam o impedimento ao aprofundamento do sistema radicular, promovido pelas camadas coesas superficiais e suas implicações no suprimento de água e nutrientes para as plantas;.este é um dos motivos pelos quais Souza et al. (2002), ressaltam que quaisquer interferências de uso e manejo nos solos dos tabuleiros devem passar, necessariamente, pela melhoria do sistema radicular em profundidade, buscando-se aumentar a superfície de absorção de nutrientes e, principalmente, de água pelas plantas.

As camadas coesas são estruturas pedogenéticas típicas dos solos dos tabuleiros costeiros e, quando secas, são duras a extremamente duras, tornando-se friáveis ou firmes quando úmidas (Jacomine, 2001). Se presentes no solo, podem apresentar grande variabilidade, tanto na espessura quanto no grau de adensamento e localização no perfil. Em estudo conduzido por Cintra et al. (2004), foram detectadas camadas coesas com características distintas, seja em grau de adensamento ou na posição ocupada no perfil.

Um aspecto singular dessas camadas é que, na presença de água, a expressão do adensamento é reduzida, em parte ou totalmente, fazendo com que o manejo da irrigação tanto na freqüência quanto no volume de água, passe a ter grande importância na otimização desta prática; assim, por ser o coqueiro anão verde uma variedade que, por sua alta taxa de transpiração, consome mais água que as demais (Nogueira et al., 1998), motivo pelo qual não se adapta facilmente às condições de plantio em sequeiro, o rigor no manejo da irrigação nesses solos deverá ser maior que o usual.

Um dos principais desafios para o estabelecimento de um sistema produtivo de coqueiro anão verde eficiente nos solos coesos dos tabuleiros costeiros, diz respeito, portanto, ao aprofundamento do seu sistema radicular. Miranda et al. (2003), ressalta que, apesar da adaptação do sistema radicular do coqueiro anão verde de Jequi às condições físicas e hídricas dos solos, as radicelas situadas próximas à superfície são vulneráveis ao estresse hídrico e, ainda, que a ocorrência de camadas coesas pode dificultar o desenvolvimento das raízes.

Em estudo conduzido, Cintra et al. (2005), em uma das principais áreas de exploração de coqueiro anão verde dos tabuleiros costeiros, ao norte do Estado de Sergipe, detectaram que $56 \%$ das raízes estavam concentrados entre 20 e $60 \mathrm{~cm}$ de profundidade sendo que 21\% destas, nos primeiros $20 \mathrm{~cm}$, a partir da superfície do solo. A grande concentração das raízes nas camadas superficiais foi relacionada à presença de camada coesa fortemente adensada.

Face ao exposto e para que o agronegócio do coqueiro anão verde tenha sucesso nos tabuleiros costeiros, será necessário investir em tecnologias geradas no meio real, respeitando-se as características do meio ambiente que tenham, como um dos principais pressupostos, a existência de camadas coesas superficiais. Esses cuidados deverão reduzir os fatores restritivos ao aprofundamento das raízes do coqueiro, que se refletem, via de regra, em baixa capacidade de absorção de água e nutrientes.
Objetivou-se com o estudo, avaliar o efeito de volumes de água aplicados por microaspersão, em solo coeso dos Tabuleiros Costeiros, no aprofundamento das raízes de coqueiro anão verde.

\section{MATERIAL E MÉTODOS}

O experimento foi conduzido na empresa agrícola $\mathrm{H}$. Dantas, localizada no Distrito de Irrigação Platô de Neópolis, Nordeste do Estado de Sergipe. O clima da região, segundo a classificação de Köppen, é do tipo tropical chuvoso com verão seco e precipitação pluvial em torno de $1200 \mathrm{~mm}$ anuais, com chuvas concentradas nos meses de abril a setembro; a altitude é de aproximadamente $90 \mathrm{~m}$ e o solo estudado foi classificado como Argissolo Amarelo, com classificação textural Areia Franca/Franco Arenosa; a temperatura média anual é de $25^{\circ} \mathrm{C}$, sendo o mês de agosto o mais frio e o de março o mais quente; a umidade média anual do ar é de 76,8\%, e os meses de maio a agosto apresentam maior umidade relativa. O relevo é plano com ondulações suaves.

A caracterização física do solo, composta por análise granulométrica, densidade do solo, porosidade total, macro e microporosidade, foi realizada em camadas de $0,20 \mathrm{~m}$, até 1,2 m de profundidade, utilizando-se metodologias descritas no manual de métodos da Embrapa (EMBRAPA, 1997).

A cultura utilizada no experimento foi o coqueiro anão verde, em plantios com espaçamento 7,5 x 7,5 x 7,5 m, configurado em triângulo eqüilátero e perfazendo 205 plantas por hectare, com idade em torno de dez anos. O sistema de irrigação utilizado foi o de microaspersão com dois emissores por planta, distanciados $0,80 \mathrm{~m}$ em lados opostos do estipe, com vazão média de $35 \mathrm{~L} \mathrm{~h}^{-1}$. Os coqueiros foram adubados com base na análise de fertilidade nas mesmas dosagens, para todos os tratamentos. O delineamento experimental foi inteiramente ao acaso com três tratamentos de volumes de água $\left(150,100\right.$ e $\left.50 \mathrm{~L} \mathrm{~d}^{-1}\right)$ e quatro repetições. Os dados de densidade de raízes (cm de raízes por 0,56 $\mathrm{m}^{2}$ de quadrícula), variável dependente do estudo, foram submetidos a uma análise de variância, segundo o delineamento de tratamentos em faixas considerando-se, como tais, os tratamentos de irrigação (150, 100 e $\left.50 \mathrm{~L} \mathrm{~d}^{-1}\right)$ e as profundidades de amostragem $(0,0-0,2,0,2-0,4,0,4-0,6$, 0,6-0,8, 0,8-1,0 m).

A avaliação da distribuição das raízes no solo foi feita em 12 trincheiras (04 por tratamento), com dimensões de 2,80 $\mathrm{x} 1,20 \mathrm{x} 1,20 \mathrm{~m}$. O preparo da parede da trincheira consistiu de escarificação com rolo de prego, seguida de limpeza e pintura de cada raiz, individualmente, com tinta branca (Cintra \& Neves, 1996). Utilizou-se a técnica de processamento e análise de imagens de raízes fotografadas com câmara digital em quadrículas de 0,20 x 0,20 m, dispostas sobre uma das paredes da trincheira; para tratamento das imagens utilizou-se o sistema integrado para análise de raízes e cobertura de solo, SIARCS (Cruvinel et al., 1996). O tamanho da quadrícula referência neste estudo foi de $0,56 \mathrm{~m}^{2}(0,20 \mathrm{~m}$ de profundidade por 2,8 m de distância lateral em relação ao 
estipe do coqueiro); a opção por este tamanho se deveu ao fato de se buscar apenas informações sobre a distribuição das raízes por profundidade.

\section{RESULTADOS E DISCUSSÃO}

Pode-se observar na Tabela 1, o caráter arenoso do solo estudado, o aumento gradual em profundidade dos teores de argila e a elevada proporção das frações de areia classificadas como média e fina. Segundo Jacomine (2001), tanto os sedimentos da Formação Barreiras quanto as coberturas sobre rochas cristalinas, responsáveis pela formação dos solos dos tabuleiros costeiros, são constituídos de materiais argilosos, argilo-arenosos ou arenosos, porém sempre bastante meteorizados e pobres em ferro. Quanto à mineralogia das frações areia e da argila, há predomínio quase exclusivo de quartzo na areia, sendo a fração argila constituída quase totalmente por caulinita. Essas características, relacionadas aos tabuleiros costeiros conduzem, com freqüência, à formação de solos com camadas coesas superficiais.

Nota-se, na Figura 1, a existência de uma camada fortemente adensada $\left(1,71 \mathrm{~kg} \mathrm{dm}^{-3}\right)$, entre 0,20 e $0,40 \mathrm{~m}$ de profundidade. A possibilidade de se tratar de uma camada coesa fica evidente ao se verificar que, na Tabela 2 , os valores de macroporosidade são, nesta mesma faixa de profundidade, baixos e bastante inferiores aos observados nas camadas acima e abaixo.

Camadas de solo com baixa proporção de macroporos e elevado adensamento, cujos índices sejam distintos das camadas adjacentes, são um indicador importante da existência de uma camada coesa no solo. Em estudo realizado por Nascimento (2001) em solo de tabuleiro do Norte Fluminense, o aumento da densidade do solo também apresentou correlação negativa com o volume de poros do solo.

Apresentam-se, na Figura 2, as curvas características do aprofundamento do sistema radicular do coqueiro anão verde quando submetido aos tratamentos de volumes de água. Independentemente dos tratamentos aplicados (150, 100 e $\left.50 \mathrm{~L} \mathrm{~d}^{-1}\right)$, as raízes do coqueiro se localizaram principalmente entre 0,20 e 0,40 m, mesma faixa de profundidade na qual os valores de densidade do solo foram mais elevados (Figura 1).

Pode parecer contraditório que a maior concentração de raízes e o maior adensamento do solo se situem no mesmo intervalo de profundidade; no entanto, é provável que esta coincidência resida no fato de que as raízes se concentraram no topo da camada coesa, em algum ponto entre 0,20 e

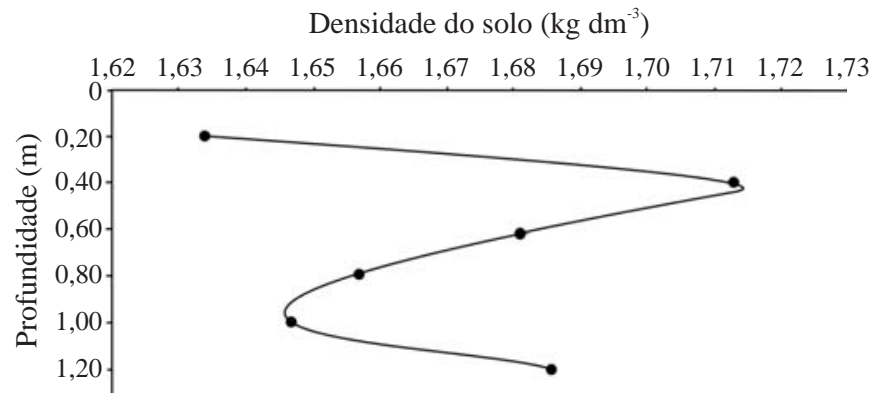

Figura 1. Curva de densidade do solo por camada de 0,2 m, na área estudada

Tabela 2. Porosidade total, macro e microporosidade do solo

\begin{tabular}{cccc}
\hline \multirow{2}{*}{ Profundidade $(\mathbf{m})$} & \multicolumn{3}{c}{ Porosidade $\left(\mathbf{m}^{\mathbf{3}} \mathbf{m}^{-3}\right)$} \\
\cline { 2 - 4 } $0,00-0,20$ & 0,20 & 0,18 & Motal \\
$0,20-0,40$ & 0,07 & 0,27 & 0,39 \\
$0,40-0,60$ & 0,11 & 0,22 & 0,34 \\
$0,60-0,80$ & 0,16 & 0,17 & 0,33 \\
$0,80-1,00$ & 0,16 & 0,17 & 0,34 \\
$1,00-1,20$ & 0,04 & 0,29 & 0,33 \\
\hline
\end{tabular}

0,40 m, impedidas de penetrar no solo devido à elevada resistência mecânica a penetração.

A expressão desse fenômeno pode ser observada na Figura 3, a qual retrata um dos perfis de enraizamento do tratamento $50 \mathrm{~L} \mathrm{~d}^{-1}$ e nela se verifica que a grande concentração das raízes está localizada em torno de $0,30 \mathrm{~m}$ de profundidade e no ponto mais próximo da planta, aproximando-se de 0,20 m da superfície do solo, a medida em que se afasta do estipe. A orientação lateral, preferencial do sistema radicular apresentada nesta Figura, é um forte indicador da existência de uma camada adensada no solo e, no caso específico, altamente restritiva ao aprofundamento das raízes.

A análise de variância dos dados de densidade de raízes não evidenciou significância para o efeito de tratamento (volumes de água), sendo que o efeito de profundidade foi muito significativo. Realizou-se o desdobramento da interação para avaliar o efeito de tratamentos dentro de cada profundidade, observando-se significância nas profundidades 0,20 a 0,40 e 0,40 a $0,60 \mathrm{~m}$. Na Tabela 3 se encontram as comparações entre as médias de tratamentos, utilizando-se o teste de Tukey a nível de $5 \%$ de probabilidade e se verifica maior densidade média de raízes entre 0,20 e $0,40 \mathrm{~m}$ de profundidade.

Tabela 1. Distribuição do tamanho das partículas minerais do solo $\left(\mathrm{g} \mathrm{kg}^{-1}\right)$ e classificação textural

\begin{tabular}{|c|c|c|c|c|c|c|c|c|c|}
\hline \multirow{2}{*}{$\begin{array}{l}\text { Profundidade } \\
\text { (m) }\end{array}$} & \multicolumn{5}{|c|}{ Distribuição da fração Areia** } & \multirow{2}{*}{ Areia Total } & \multirow{2}{*}{ Siltre } & \multirow{2}{*}{ Argila } & \multirow{2}{*}{$\begin{array}{c}\text { Classificação } \\
\text { Textual }\end{array}$} \\
\hline & AMG & $\mathbf{A G}$ & AM & AF & AMF & & & & \\
\hline $0,00-0,20$ & 45,32 & 230,37 & 384,17 & 202,56 & 29,68 & 892,11 & 50,23 & 57,66 & Areia \\
\hline $0,20-0,40$ & 25,07 & 165,71 & 370,41 & 263,62 & 38,51 & 863,32 & 51,44 & 85,24 & Areia Franca \\
\hline $0,40-0,60$ & 62,30 & 187,41 & 301,66 & 233,28 & 47,24 & 831,88 & 65,30 & 102,82 & Franco Arenoso \\
\hline $0,60-0,80$ & 49,41 & 194,88 & 289,58 & 218,47 & 40,98 & 793,31 & 86,29 & 120,40 & Franco Arenoso \\
\hline $0,08-1,00$ & 45,33 & 152,35 & 291,33 & 235,70 & 46,74 & 771,44 & 98,15 & 130,41 & Franco Arenoso \\
\hline
\end{tabular}

${ }^{\star *}$ AMG - Areia muito grossa (2 a $\left.1 \mathrm{~mm}\right) ; A G$ - Areia grossa (1 a $\left.0,5 \mathrm{~mm}\right) ; \mathrm{AM}$ - Areia média $(0,5 \mathrm{a} 0,25 \mathrm{~mm}) ; \mathrm{AF}$ - Areia fina $(0,25$ a $0,1 \mathrm{~mm}) ; \mathrm{AMF}$ - Areia muito fina $(0,1$ a $0,05 \mathrm{~mm})$ 


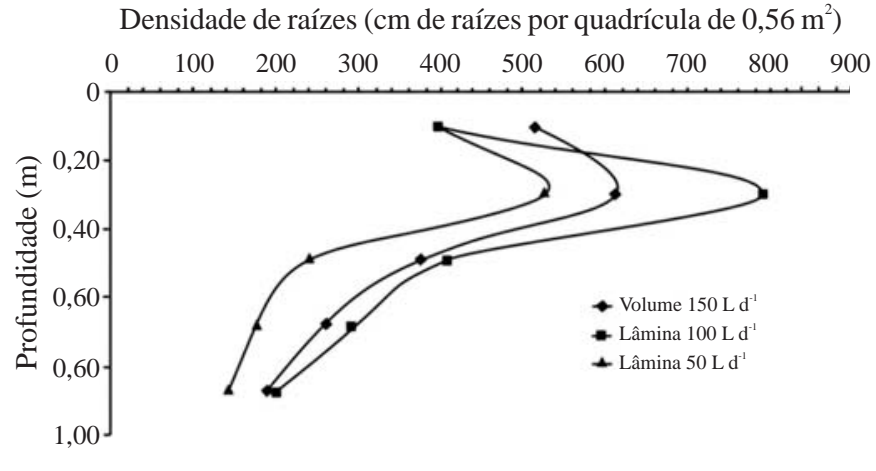

Figura 2. Distribuição do sistema radicular de coqueiro anão verde por camada de $0,20 \mathrm{~m}$ de profundidade, em função dos volumes de água aplicados

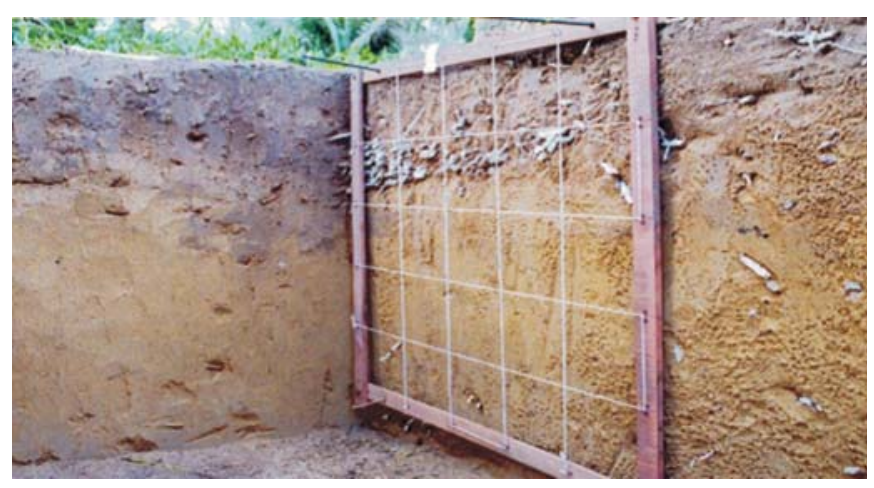

Figura 3. Visualização da distribuição horizontal e vertical das raízes de coqueiro Anão Verde, no tratamento $50 \mathrm{~L} \mathrm{~d}^{-1}$. Dimensões das quadrículas: $0,20 \times 0,20 \mathrm{~m}$

Nos resultados referentes ao desdobramento da interação entre os efeitos principais, nota-se que na camada 0,20 e $0,40 \mathrm{~m}$ a densidade média das raízes no tratamento $100 \mathrm{~L} \mathrm{~d}^{-1}$ foi superior aos tratamentos 50 e $150 \mathrm{~L} \mathrm{~d}^{-1}$, os quais não diferiram estatisticamente entre si; já entre 0,40 e $0,60 \mathrm{~m}$, os tratamentos 100 e $150 \mathrm{~L} \mathrm{~d}^{-1}$ se igualaram estatisticamente, sendo que $150 \mathrm{~L} \mathrm{~d}^{-1}$ também não diferiu do volume $50 \mathrm{~L} \mathrm{~d}^{-1}$. Ressalta-se a pequena diferença entre a densidade média das raízes e esses dois tratamentos

Tabela 3. Comparações de médias dos tratamentos volumes de água em $\mathrm{cm}$ de raiz por quadrícula de $0,56 \mathrm{~m}^{2}$, dentro de cada profundidade, pelo teste de Tukey ao nível de $5 \%$ de probabilidade

\begin{tabular}{|c|c|c|c|c|c|}
\hline \multirow{2}{*}{$\begin{array}{l}\text { Volumes de } \\
\text { água }\left(L d^{-1}\right)\end{array}$} & \multicolumn{5}{|c|}{ Intervalos de Profundidades (m) } \\
\hline & $0-0,20$ & $0,20-0,40$ & $0,40-0,60$ & $0,60-0,80$ & $0,80-1,00$ \\
\hline 50 & $409,002 a^{1}$ & $543,070 \mathrm{~b}$ & $244,430 \mathrm{~b}$ & 177,765 a & $141,255 \mathrm{a}$ \\
\hline 100 & $406,462 \mathrm{a}$ & $822,592 \mathrm{a}$ & $417,542 \mathrm{a}$ & 297,290 a & $200,735 \mathrm{a}$ \\
\hline 150 & $528,980 \mathrm{a}$ & $633,852 \mathrm{~b}$ & 386,695 a & $265,980 \mathrm{a}$ & $192,152 \mathrm{a}$ \\
\hline $\begin{array}{l}\text { Medias de } \\
\text { Profundidade }\end{array}$ & $447,815 B^{2}$ & $666,505 \mathrm{~A}$ & $349,556 \mathrm{BC}$ & $247,012 \mathrm{C}$ & $178,097 \mathrm{C}$ \\
\hline \multicolumn{6}{|c|}{ Média geral $=377,787$} \\
\hline \multicolumn{2}{|c|}{$\mathrm{CV}^{2}(\%)=37,90$} & \multicolumn{2}{|c|}{ Erro padrão $0^{3}=41,331$} & \multicolumn{2}{|c|}{$\mathrm{DMS}^{3}=180,547$} \\
\hline \multicolumn{2}{|c|}{$\mathrm{CV}^{\beta}(\%)=23,49$} & \multicolumn{2}{|c|}{ Erro padrão $0^{4}=44,370$} & \multicolumn{2}{|c|}{$\mathrm{DMS}^{4}=158,230$} \\
\hline
\end{tabular}

${ }^{1}$ Médias seguidas de mesma letra minúscula na vertical não diferem significativamente entre si; ${ }^{2}$ Médias seguidas de mesma letra maiúscula na horizntal não diferem significativamente entre si; ${ }^{3}$ Estatísticas utilizadas nas comparações de profundidade;

${ }^{4}$ Estatísticas utilizadas nas comparações de tratamento dentro de profundidade
(142,265 cm de raízes por 0,56 m² $^{2}$ de área) e a DMS de 158,230 , obtida no teste.

A menor densidade média das raízes no tratamento $150 \mathrm{~L} \mathrm{~d}^{-1}$ em relação a $100 \mathrm{~L} \mathrm{~d}^{-1}$ na camada 0,20 a $0,40 \mathrm{~m}$, deve estar relacionada ao efeito negativo dos períodos de excesso de umidade e à má aeração, resultantes do acréscimo diário de $50 \mathrm{~L}$ de água por dia; por outro lado, a maior densidade de raízes desses dois tratamentos, em todas as profundidades e em relação ao tratamento $50 \mathrm{~L} \mathrm{~d}^{-1}$ se deve, provavelmente, à redução da expressão do adensamento das camadas coesas, proporcionada pelo maior umedecimento do perfil do solo.

Este umedecimento deve ter sido o responsável pela maior densidade das raízes nos tratamentos 150 e $100 \mathrm{~L} \mathrm{~d}^{-1}$ na camada 0,40 a 0,60 m (Figura 2, Tabela 3) cujos resultados permitem a interpretação de que a quantidade de água adicionada nos tratamentos 150 e $100 \mathrm{~L} \mathrm{~d}^{-1}$ foi suficiente para umedecer o solo em toda a extensão ocupada pelo sistema radicular; da mesma forma, pode-se inferir que no tratamento irrigado com $50 \mathrm{~L}$ de água $\mathrm{d}^{-1}$ a quantidade adicionada tenha sido insuficiente para reduzir a expressão do adensamento da camada coesa contribuindo para que a mesma atuasse como barreira ao aprofundamento das raízes.

Giarola \& Silva (2003), enfatizam que as raízes que crescem em solos coesos e, simultaneamente, os secam, contribuem para aumentar progressivamente o impedimento mecânico do solo e reduzir mais ainda a taxa de crescimento radicular. Nos perfis mais arenosos dos solos coesos dos tabuleiros costeiros, a exemplo do solo em estudo, o simples umedecimento em profundidade já reduz sensivelmente a resistência mecânica à penetração das raízes (Ribeiro, 2001).

Com base na distribuição espacial das raízes apresentada na Figura 4, pode-se observar que os perfis de enraizamento dos tratamentos 150 e $100 \mathrm{~L} \mathrm{~d}^{-1}$ (Figuras 4A e 4B), são similares e se distribuem uniformemente por toda a área, tanto lateralmente como em profundidade; em ambos os casos, a maior densidade das raízes se encontra no primeiro quadrante de $1,00 \times 0,70 \mathrm{~m}$ e diferem entre si apenas pela maior densidade de raízes do tratamento $100 \mathrm{~L} \mathrm{~d}^{-1}$ na área mais próxima ao estipe do coqueiro, onde o predomínio das cores mais escuras é visivelmente maior.

Situação bastante diversa e análoga à apresentada na Figura 3, ocorre com o tratamento $50 \mathrm{~L} \mathrm{~d}^{-1}$ (Figura 4C), cuja distribuição espacial das raízes se concentra nos primeiros 0,40 m ocupando, praticamente, toda a extensão lateral; esta restrição ao aprofundamento das raízes e estímulo ao crescimento lateral, é uma indicação de que os 50 litros de água aplicados por dia neste tratamento foram insuficientes para umedecer a camada coesa, a ponto de reduzir a expressão do seu adensamento impedindo, assim, que as raízes se aprofundassem no solo.

Várias outras estratégias, além da variação na quantidade de água aplicada via irrigação, podem ser utilizadas para minimizar o efeito da coesão dos solos na distribuição do sistema radicular das plantas. Cintra et al. (2005), compararam sistemas de irrigação localizada (microaspersão, gotejamento) na distribuição do sistema radicular de coqueiro anão verde e concluíram que os sistemas por gotejamento 


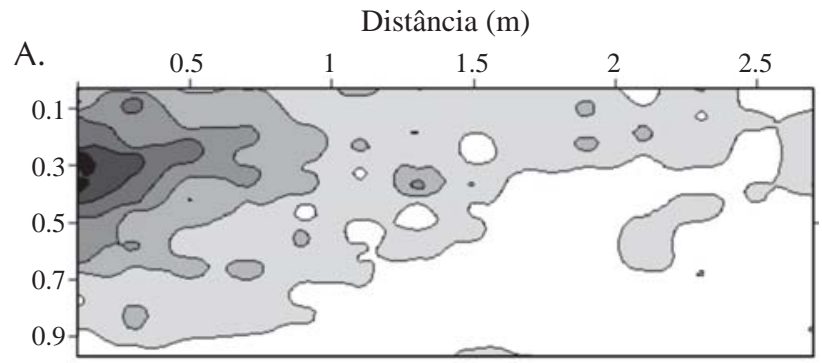

B.

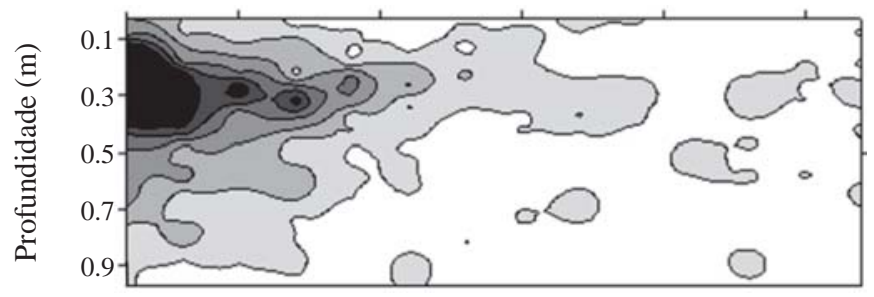

C.

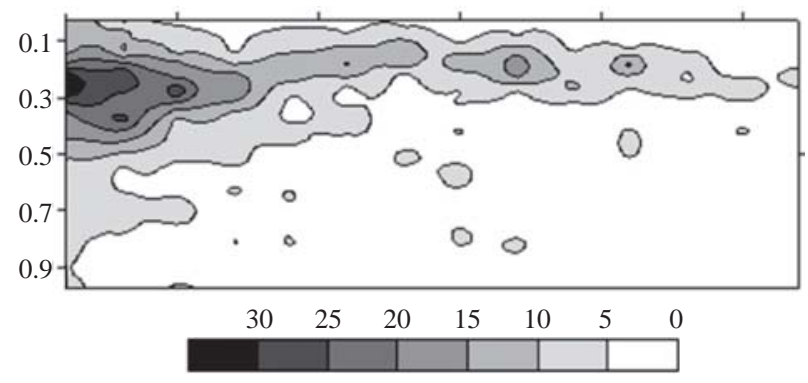

Figura 4. Distribuição espacial da densidade de raízes de coqueiro anão verde $\left(\mathrm{cm}\right.$ de raízes por quadrícula de $\left.0,56 \mathrm{~m}^{2}\right)$ nos tratamentos 150 (A), 100 (B) e $50 \mathrm{~L} \mathrm{~d}^{-1}(\mathrm{C})$

foram significativamente mais eficientes que o de microaspersão, para aprofundamento das raízes dessa espécie em solo de tabuleiro costeiro. Resultados similares com a cultura da mangueira, também em solo de tabuleiro, foram obtidos por Coelho et al. (2001), os quais evidenciaram a superioridade do sistema de irrigação localizada por gotejamento em relação ao sistema por microaspersão.

A ausência de água no solo coeso favorece o processo de polimerização e precipitação da sílica e de outros constituintes sílico-aluminosos amorfos, promovendo a expressão máxima da coesão; por outro lado, o umedecimento do solo promove a despolimerização da sílica e de outros aluminossilicatos contribuindo, assim, para promover a condição de friabilidade do solo (Araújo Filho, 2001). O autor ressalta, entretanto, que estudos mais pormenorizados são necessários para comprovar ou descartar a interferência da água nos processos de secamento e friabilidade.

\section{CONCLUSÕES}

1. A aplicação de 50 L de água por dia, via microaspersão, foi insuficiente para reduzir a expressão do adensamento da camada coesa do solo estudado, de modo a permitir o aprofundamento das raízes do coqueiro anão verde.
2. Os volumes de 100 e 150 L de água por dia apresentaram comportamento semelhante entre si e propiciaram melhores condições de desenvolvimento lateral e em profundidade das raízes de coqueiro anão verde

\section{AGRADECIMENTOS}

Agradecimentos especiais à Empresa H. Dantas, pela parceria no desenvolvimento desse estudo.

\section{LITERATURA CITADA}

Araújo Filho, J. C. de. Investigações preliminares sobre a pedogênese de horizontes coesos em solos dos tabuleiros costeiros do Nordeste do Brasil. In:Workshop Coesão em Solos dos Tabuleiros Costeiros. 2001, Aracaju. Anais... Aracaju: Embrapa Tabuleiros Costeiros, 2001. p.123.

Cintra, F. L. D.; Neves, C. S. V. J. Aspectos metodológicos do estudo do sistema radicular de plantas perenes através de imagens. Boletim Informativo da Sociedade Brasileira de Ciência do Solo, v.21, n.3, p.91-94, 1996.

Cintra, F. L. D.; Portela, J. C.; Nogueira, L. C. Caracterização física e hídrica em solos dos tabuleiros costeiros no distrito de irrigação Platô de Neópolis. Revista Brasileira de Engenharia Agrícola e Ambiental, v.8, n.1, p.45-50, 2004.

Cintra, F. L. D.; Portela, J. C.; Nogueira, L. C.; Gornat, B. Distribuição de raízes de coqueiro anão verde sob sistemas de irrigação localizada em solo dos tabuleiros costeiros. http://www.cpatc.embrapa.br. Boletim de Pesquisa 6. Out. 2005.

Coelho, E. F.; Oliveira, F. das C.; Araújo, E. C. E.; Vasconcelos, L. F. L.; Lima, D. M. Distribuição do sistema radicular de mangueira sob irrigação localizada em solo arenoso de Tabuleiros Costeiros. Revista Brasileira de Fruticultura, v.23, n.2, p.250-256, 2001.

Cruvinel, P. E.; Crestana, S.; Jorge, L. A. C. de. Métodos e aplicações do processamento de imagens digitais. In: Crestana, S.; Cruvinel, P. E.; Mascarenhas, S.; Biscegli, C. I.; Martin Neto, L.; Colnago, L. A. (ed.). Instrumentação agropecuária; contribuições no limiar do novo século. Brasília: Embrapa SPI, 1996. cap.3, p.91-151.

EMBRAPA - Empresa Brasileira de Pesquisa Agropecuária. Manual de métodos de análise de solo. 2.ed. Rio de Janeiro: Embrapa SNLCS, 1997. 212p.

Giarola, N. F. B.; Silva, A. P, da. Conceitos sobre solos coesos e hardsetting. Scientia Agrícola, v.59. n.3, p.613-620, 2003.

Jacomine, P. K. T. Evolução do conhecimento sobre solos coesos no Brasil. In: Workshop Coesão em Solos dos Tabuleiros Costeiros, 2001, Aracaju. Anais... Aracaju: Embrapa Tabuleiros Costeiros, 2001. p.19.

Miranda, F. R. de; Freitas, J. de A. D. de; Montenegro, A. A. T.; Crisóstomo, L. A.. Distribuição das raízes de coqueiro anão verde para manejo da irrigação e a aplicação de fertilizantes. http://www.cnpat.embrapa.br, Circular Técnica 16. Dez. 2003. 
Nascimento, G. B. do. Caracterização dos solos e avaliação de propriedades edáficas em ambientes de tabuleiros costeiros da Região Norte Fluminense (RJ). Seropédica: UFRRJ, 2001. 162p. Dissertação Mestrado

Nogueira, L. C.; Nogueira, L. R. Q.; Miranda, F. R. de. Irrigação do coqueiro. In: Ferreira, J. M. S.; Warwick, D. R. N.; Siqueira, L. A. (eds). A cultura do coqueiro no Brasil. Aracaju: Embrapa CPATC, 1998. cap.7, p.159-187.
Ribeiro, M. R. Características morfológicas dos horizontes coesos dos solos dos Tabuleiros Costeiros. In:. Workshop Coesão em Solos dos Tabuleiros Costeiros, 2001, Aracaju. Anais... Aracaju: Embrapa Tabuleiros Costeiros, 2001. p.161.

Souza, L. da S.; Borges, A. L.; Cintra, F. L. D.; Souza, L. D.; Ivo, W. M. P. de M. Perspectivas de uso dos solos dos tabuleiros costeiros. In: Araújo, Q. R. de (org.). 500 anos de uso do solo no Brasil. Ilhéus: Editus/UESC, 2002. p.521-579. 